\title{
Functional Consequences of
} Intracellular Proline Levels Manipulation Affecting PRODH/POX-Dependent Pro-Apoptotic Pathways in a Novel in Vitro Cell Culture Model

\author{
Ilona Zareba ${ }^{a}$ Arkadiusz Surazynskia Marcin Chrusciel ${ }^{b}$ Wojciech Miltyk ${ }^{c}$ \\ Milena Doroszko ${ }^{\mathrm{b}}$ Nafis Rahman ${ }^{\mathrm{b}}$ Jerzy Palka \\ a Department of Medicinal Chemistry, Medical University of Bialystok, Bialystok, Poland; 'bepartment of \\ Physiology, Institute of Biomedicine, University of Turku, Turku, Finland; 'Department of Pharmaceutical \\ Analysis, Medical University of Bialystok, Bialystok, Poland
}

\section{Key Words}

Apoptosis - Collagen biosynthesis - MCF-7 breast cancer cells • Proline $•$ Proline dehydrogenase/proline oxidase.

\begin{abstract}
Background/Aims: The effect of impaired intracellular proline availability for proline dehydrogenase/proline oxidase (PRODH/POX)-dependent apoptosis was studied. Methods: We generated a constitutively knocked-down PRODH/POX MCF-7 breast cancer cell line (MCF-7 7hPRODH/POX) $^{\text {s }}$ as a model to analyze the functional consequences of impaired intracellular proline levels. We have used inhibitor of proline utilization in collagen biosynthesis, 2-metoxyestradiol (MOE), inhibitor of prolidase that generate proline, rapamycin (Rap) and glycyl-proline (GlyPro), substrate for prolidase. Collagen and DNA biosynthesis were evaluated by radiometric assays. Cell viability was determined using Nucleo-Counter NC-3000. The activity of prolidase was determined by colorimetric assay. Expression of proteins was assessed by Western blot and immunofluorescence bioimaging. Concentration of proline was analyzed by liquid chromatography with mass spectrometry. Results: PRODH/POX knockdown decreased DNA and collagen biosynthesis, whereas increased prolidase activity and intracellular proline level in MCF-7 $7_{\text {ShPODH/POX }}$ cells. All studied compounds decreased cell viability in MCF-7 and MCF-7 7 SPRODH/POX cells. DNA biosynthesis was similarly inhibited by Rap and MOE in both cell lines, but GlyPro inhibited the process only in MCF-7 shPRODH/POX $^{2}$ and MOE+GlyPro only in MCF-7 cells. All the compounds inhibited collagen biosynthesis, increased prolidase activity and cytoplasmic proline level in MCF- $7^{\text {shPRODH/POX }}$ cells and contributed to the induction of pro-survival mode only in MCF-7 $7^{\text {shPRODH/POX }}$ cells. In contrast, all studied compounds upregulated expression of pro-apoptotic protein only in MCF-7 cells. Conclusion: PRODH/POX was confirmed as a driver of apoptosis and proved the eligibility of MCF- $7^{\text {shPRODH/POX }}$ cell line as a highly effective model to elucidate the different mechanisms underlying proline utilization or generation in PRODH/POX-dependent pro-apoptotic pathways.




\section{Cellular Physiology Cell Physiol Biochem 2017;43:670-684

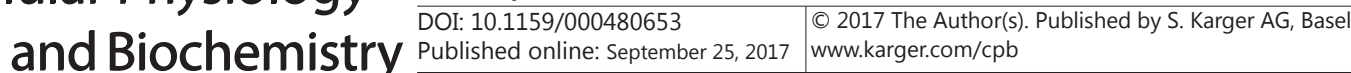 \\ Zareba et al.: A Viable Functional In Vitro Model for Proline Oxidase Research}

\section{Introduction}

An increased proline biosynthesis and accumulation in neoplastic cells has been shown earlier $[1,2]$, however the mechanism of this process and its metabolic consequences on the cell functions are not fully understood. Important source of proline are extracellular collagen degradation products undergoing internalization and further degradation to free amino acids in lysosomes or cytoplasm [3]. Essential group of collagen degradation products are iminodipeptides (e.g. glycyl-proline) that are degraded to amino acids in cytoplasm by specific iminodipeptidase, prolidase [E.C.3.4.13.9]. Cytoplasmic prolidase activity is important in regulation of proline accumulation and proline-dependent metabolic responses in the cell $[4,5]$.

Proline play an important role in inhibition of degradation of hypoxia-inducible factor 1-alpha (HIF-1 $\alpha$ ) a transcription factor that activates several pro-angiogenic and neoplastic genes such as vascular endothelial growth factor (VEGF), transforming growth factor (TGF) or tumor necrosis factor (TNF) $[4,6,7]$. The mechanisms that utilize proline are collagen biosynthesis and proline conversion into pyrroline-5-carboxylic acid (P5C) [4, 8-10]. The second process is catalyzed by mitochondrial proline dehydrogenase/proline oxidase (PRODH/POX). It has been proposed that cytoplasmic proline that enters mitochondria is a sensor of cellular energy status [11]. This usually happens under low glucose stress, when PRODH/POX activation induces ATP production for energy supply and cell survival [12-14]. On the other hand, conversion of mitochondrial proline into P5C by PRODH/POX generates superoxide anion that may contribute to ROS-dependent intrinsic and extrinsic apoptotic pathways [11, 12, 15-18]. In the presence of proline, overexpression of PRODH/ POX causes cytochrome $\mathrm{c}$ release from mitochondria to cytosol and activation of caspase- 9 and caspase-3 [16]. Moreover, it was showed that up-regulation of PRODH/POX contributes to activation also caspase-8 in the extrinsic apoptotic pathway mainly because of its ability to stimulate expression of TNF-related apoptosis inducing ligand (TRAIL) and death receptor 5 (DR5) $[11,16]$. Therefore, PRODH/POX may play dual role, but the mechanism that switches PRODH/POX from tumor growth inhibiting to growth stimulating factor is unknown. One of the major limiting factors in this research aspect was lack of an in vitro model that would facilitate the intracellular proline manipulation and could be helpful in showing the mechanistic aspects of PRODH/POX roles as tumor inhibiting or stimulating factors.

In view of an important role of availability of proline in the regulation of apoptosis/ survival, our goal was to generate a constitutively stable PRODH/POX knocked-down cell line (MCF-7shPRODH/POX) to inhibit proline utilization into P5C. Accordingly, PRODH/POX knockdown contributed to decrease in collagen biosynthesis and increase in prolidase activity in MCF-7 cells. We further used different treatments and methods to increase the free pool of cytoplasmic level of proline. Finally, we measured cell viability, collagen biosynthesis, prolidase activity, DNA biosynthesis and tested the induction of apoptosis by its markers - all to establish the functionality and eligibility of MCF-7 $7_{\text {shPRODH/POX }}$ cell line as an in vitro model to study proline utilization or stimulation in PRODH/POX-dependent pro-apoptotic pathways.

\section{Materials and Methods}

Design of experiment

To determine the role of proline metabolism in apoptosis in MCF-7 shPRoDH/POX and wild-type MCF-7 control breast cancer cells, we designed several experimental conditions that limit utilization of proline for HIF-1 $\alpha$ transcriptional activity, collagen biosynthesis and prevent proline generation by prolidase activity. 2-metoxyestradiol (MOE) was used as an inhibitor of HIF-1 $\alpha$ and collagen biosynthesis while rapamycin (Rap) to inhibit mTOR and prolidase activity. In order to increase cytoplasmic level of proline, glycyl-proline (GlyPro) was used as a substrate for prolidase. 


\section{Cellular Physiology Cell Physiol Biochem 2017;43:670-684 \begin{tabular}{ll|l} 
DOI: 10.1159/000480653 & $\begin{array}{l}\text { O } 2017 \text { The Author(s). Published by S. Karger AG, Basel } \\
\text { www.karger.com/cpb }\end{array}$
\end{tabular} \\ Zareba et al.: A Viable Functional In Vitro Model for Proline Oxidase Research}

\section{Cell lines and culture}

Brest cancer cell line MCF-7 was obtained from ATCC (HTB-22, ATCC, Manassas, VA, USA). The MCF-7 and MCF-7 shPRoDH/POX cells were maintained in DMEM and 5\% fetal bovine serum (FBS, Gibco, Thermo Fisher Scientific, Waltham, Massachusetts, USA), $50 \mathrm{IU} / \mathrm{ml}$ penicillin (Gibco), and $50 \mu \mathrm{g} / \mathrm{ml}$ streptomycin (Gibco) at $37^{\circ} \mathrm{C}$ in a humidified atmosphere in the presence of $5 \% \mathrm{CO}_{2}$. MCF-7 and MCF-7 ${ }^{\text {sPRODH } / \text { POX }}$ cells were cultured in glutamine-free DMEM (Gibco) and treated for $24 \mathrm{~h}$ with rapamycin (Rap, 22, $85 \mu \mathrm{g} / \mathrm{ml}$ ), 2-metoxyestradiol (MOE, 22, $65 \mu \mathrm{g} / \mathrm{ml}$ ), glycyl-proline (GlyPro, 17, $22 \mu \mathrm{g} / \mathrm{ml}$ ) or the combination of MOE and GlyPro (22, $65 \mu \mathrm{g} / \mathrm{ml}$ and $17,22 \mu \mathrm{g} / \mathrm{ml}$, respectively).

\section{shRNA-based PRODH knock-down}

To knock-down expression of $P R O D H, 3$ pairs of short herpins complement single-stranded DNA oligonucleotides were designed using AsiDesigner online tool (http://sysbio.kribb.re.kr:8080/AsiDesigner/ menuDesigner.jsf) (Table 1). HPLC purified oligonucleotides were ordered from Genomed (Warsaw, Poland). Annealed double-stranded oligonucleotides were cloned into pSuper.puro expression vector (OligoEngine, Seattle, WA, USA) via BgIII and HindIII restriction sites using T4 DNA ligase (Thermo Fisher Scientific, Waltham, Massachusetts, USA). Positive colonies of heat-shock transformed NEB 10-beta competent $E$. coli bacteria (Bio Labs, Ipswich, United Kingdom), were verified by PCR, restriction enzyme BgIII and HindIII digestion (Thermo Fisher Scientific,) and gel electrophoresis. Amplified plasmid DNA was extracted and purified by NucleoSpin $\circledast$ Plasmid (Macherey-Nagel, Düren, Germany). Oligonucleotide sequences (shRNA oligos) of PRODH are shown in Table 1.

MCF-7 cells were cultured in 6-well plate $\left(1 \times 10^{5}\right.$ cells per well in $2 \mathrm{ml}$ culture media). Twenty-four hours later, cells were transfected with three different shRNA expressing vectors or shRNA non-targeting control using Lipofectamin ${ }^{\mathrm{TM}} 2000$ (Invitrogen, Thermo Fisher Scientific) in OptiMem media (Gibco) according to the manufacturer's protocol. $P R O D H$ shRNA-expressing cells were selected using puromycin antibiotic (Invitrogen) with previously optimized concentration of $1 \mu \mathrm{g} / \mathrm{ml}$. The MCF-7 $7^{\text {shPRODH} / \mathrm{POX}}$ stable transfected cells were generated from selecting the single puromycin-resistant " best clone (highest knocked down PRODH/POX) " and was further characterized and used in this study.

\section{Western blot}

Cell lysates of PRODH/POX shRNA stably transfected MCF-7 cell clones and MCF-7 cell controls were harvested and subjected to SDS-PAGE in $10 \%$ polyacrylamide gel electrophoresis [ $11 \mathrm{~h}, 125 \mathrm{~V}$, room temperature (RT)]. The protein was transferred to $0.2 \mu \mathrm{m}$ pore-sized nitrocellulose (wet transfer, $1 \mathrm{~h}, 100 \mathrm{~mA}, \mathrm{RT}$ ).

Table 1. Oligonucleotide sequences (shRNA oligos) of PRODH used in the study are in bold (tv - transcript variant)

\begin{tabular}{|c|c|c|c|}
\hline Name & & Sequences $\left(5^{\prime}-3^{\prime}\right)$ & Target \\
\hline \multirow{3}{*}{ PRODH } & F: & gatccccCTAGGACAGAGGCTATTCAACttcaagagaGTTGAATAGCCTCTGTCCTAGtttta & PRODH tv. \\
\hline & & & $1502-$ \\
\hline & & & 522 \\
\hline \multirow[t]{2}{*}{ shRNA 2} & R: & agcttaaaaaCTAGGACAGAGGCTATTCAACtctcttgaaGTTGAATAGCCTCTGTCCTAGggg & PRODH ty ? \\
\hline & & & 87-107 \\
\hline \multirow[b]{2}{*}{ PRODH } & F: & gatccccGCATGTGTGACCAGATCAGCTttcaagagaAGCTGATCTGGTCACACATGCtttt & PRODH tv. 1 \\
\hline & & & $1790-1810$ \\
\hline \multirow[t]{2}{*}{ shRNA 1} & R: & agcttaaaaaGCATGTGTGACCAGATCAGCTttcttgaaAGCTGATCTGGTCACACATGCggg & PRODH tv. 2 \\
\hline & & & 1374-1394 \\
\hline \multirow{3}{*}{ PRODH } & F: & gatccccGTGTACAAGTACGTGCCCTATttcaagagaATAGGGCACGTACTTGTACACtttta & PRODH tv. \\
\hline & & & $11837-$ \\
\hline & & & 1857 \\
\hline \multirow[t]{2}{*}{ shRNA 3} & R: & agcttaaaaaGTGTACAAGTACGTGCCCTATtctcttgaaaTAGGGCACGTACTTGTACACggg & PRODH tv. 2 \\
\hline & & & $1422-1442$ \\
\hline
\end{tabular}




\section{Cellular Physiology Cell Physiol Biochem 2017;43:670-684

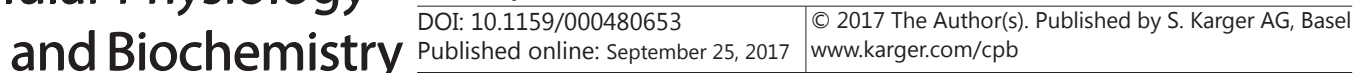 \\ Zareba et al.: A Viable Functional In Vitro Model for Proline Oxidase Research}

After the transfer membranes were blocked with 5\% non-fat dry milk (BioRad, Hercules, Kalifornia, USA) in TBS-T (20 mmol/l Tris-HCl, $150 \mathrm{mmol} / \mathrm{l} \mathrm{NaCl}, 0.05 \%$ Tween 20, pH 7.4) and incubated with following antibodies: goat monoclonal anti-PRODH/POX [EB11136, Everest Biotech, Upper Heyford, UK, 1:1000], purified mouse anti-human p53 [554169, Becton, Dickinson and Company (B\&D), New Jersey, USA, 1:1000], purified mouse anti-human HIF-1 $\alpha$ [610959, B\&D, 1:1000], rabbit anti-caspase-3 [\#9665, Cell Signaling (CS), Danvers, USA, 1:1000], rabbit anti-cleaved-caspase-3 [\#9664, CS, 1:1000], rabbit anti-caspase-9 [\#9508, CS, 1:1000], mouse anti-cleaved-caspase-9 [\#7237, CS, 1:1000], rabbit anti-PARP [\#9542, CS, 1:1000], rabbit anti-cleaved-PARP [\#5625, CS, 1:1000], rabbit anti-Atg7 [\#8558, CS, 1:1000], rabbit anti-Beclin-1 [\#3495, CS, 1:1000], mouse anti-NF-кB [610868, B\&D, 1:1000] and monoclonal anti- $\beta$-actin antibody produced in mouse [A2228, Sigma-Aldrich, Saint Louis, Missouri, USA] in blocking buffer. Then membranes were washed in TBS with $0.05 \%$ Tween (TBST) 3 x 15 min and incubated with anti-goat, anti-rabbit or anti-mouse HRPlinked secondary antibody at concentration 1:7500 (Sigma-Aldrich) for $60 \mathrm{~min}$ at RT with gentle agitation. After washing in TBS-T ( $5 \times 5$ min) membranes were incubated with Amersham ECL Western Blotting Detection Reagent, (GE Healthcare Life Sciences, Little Chalfont, Buckinghamshire, UK). Pictures were taken using BioSpectrum Imaging System UVP (Ultra-Violet Products Ltd, Cambridge, UK). Densitometry of western blot bands was analyzed using ImageJ software [19].

\section{Cell viability assay}

Cytotoxicity of tested substances was determined using Nucleo Counter NC-3000 (ChemoMetec, Copenhagen, Denmark). Prior the experiment MCF-7 and MCF-7 shPRoDH/Pox cells were cultured in six-well plates at $1 \times 10^{5}$ cells/well with $2 \mathrm{ml}$ of growth medium. After $24 \mathrm{~h}$ incubation of the cells with Rap, MOE, GlyPro and MOE+GlyPro, glutamine-free medium was discarded and the cells were rinsed three times with phosphate buffered saline (PBS). Then the cells were harvested, washed and stained with VitaBright-48 (VB-48) (ChemoMetec), acridine orange (AO) (ChemoMetec), propidium iodide (PI) (ChemoMetec) and analyzed using NC-3000 cell counter. Viability of the cells treated with above compounds was calculated as a percent of control.

\section{Proliferation assay}

Proliferation of MCF-7 and MCF-7 ${ }^{\text {shPRODH/POX }}$ cells was measured by [methyl- ${ }^{3} \mathrm{H}$ ] thymidine (Hartman Analytic GmbH, Braunschweig, Germany) incorporation into DNA. Prior the experiment MCF-7 and MCF$7^{\text {shPRODH/POX }}$ cells were cultured in 24-well plate at $1 \times 10^{4}$ cells/well with $1 \mathrm{ml}$ of growth medium. After $48 \mathrm{~h}$ the cells were incubated in glutamine-free DMEM (Gibco) with Rap, MOE, GlyPro and MOE+GlyPro for 24 $\mathrm{h}$ and next with $0.5 \mu \mathrm{Ci} / \mathrm{ml}$ of [methyl ${ }^{3} \mathrm{H}$ ] thymidine for $4 \mathrm{~h}$. PBS-rinsed cells were solubilized with $1 \mathrm{ml}$ of $0.1 \mathrm{~mol} / \mathrm{l}$ sodium hydroxide containing $1 \%$ SDS and $5 \mathrm{ml}$ of scintillation fluid Ultima Gold XR (Perkin Elmer, Waltham, USA). Incorporation of the tracer into DNA was measured by Liquid Scintillation Analyzer TriCarb 2810 TR (Perkin Elmer) and calculated using Quanto Smart TM software (Perkin Elmer).

\section{Collagen biosynthesis}

MCF-7 and MCF-7 $7^{\text {shPRODH/POx }}$ cells were cultured in 24-well plate at $1 \times 10^{4}$ cells/well with $1 \mathrm{ml}$ of growth medium. After $48 \mathrm{~h}$, the cells were incubated in glutamine-free DMEM (Gibco) with Rap, MOE, GlyPro or $\mathrm{MOE}+\mathrm{GlyPro}$ and $5 \mu \mathrm{Ci} / \mathrm{ml}$ of $5\left[{ }^{3} \mathrm{H}\right]$-proline (Hartman Analytic GmbH, Braunschweig, Germany) for $24 \mathrm{~h}$. Incorporation of tracer-labeled proline into collagen was measured in collagenase-digested (Clostridium histolyticum collagenase, Sigma-Aldrich) protein homogenate by Liquid Scintillation Analyzer Tri-Carb 2810 TR (Perkin Elmer) according to the method of Peterkofsky et al [20].. Results are shown as combined values of cellular and medium fractions.

\section{Determination of prolidase activity}

MCF-7 and MCF-7 ${ }^{\text {shPRODH/POX }}$ cells were incubated $24 \mathrm{~h}$ in glutamine-free DMEM media (Gibco) with Rap, MOE, GlyPro or MOE+GlyPro. Protein concentration was measured by the method of Lowry et al [21].. The activity of prolidase was determined according to the method of Myara et al [22].. Amount of released proline from synthetic substrate (GlyPro) by prolidase from cell homogenate was measured by using colorimetric method. Enzyme activity was reported as nanomoles of proline released from GlyPro, during 1 min per milligram of supernatant protein of cell homogenate.

\section{KARGER}




\section{Cellular Physiology Cell Physiol Biochem 2017;43:670-684 \begin{tabular}{l|l|l} 
and Biochemistry $10.1159 / 000480653$ & (c) 2017 The Author(s). Published by S. Karger AG, Basel \\
www.karger.com/cpb
\end{tabular} \\ Zareba et al.: A Viable Functional In Vitro Model for Proline Oxidase Research}

\section{Immunofluorescence staining}

Cells grown on a coverslip were fixed with $3.7 \%$ paraformaldehyde and permeabilized with $0.01 \%$ TritonX100. After blocking with 3\% FBS (30 min, RT), cells were incubated (1 h, RT) with following antibodies anti: purified mouse anti-human HIF-1 $\alpha$ [610959, B\&D, 1:1000], rabbit anti-caspase-3 [\#9665, CS, 1:1000], rabbit anti-cleaved-caspase-3 [\#9664, CS, 1:1000], rabbit anti-caspase-9 [\#9508, CS, 1:1000], mouse anticleaved-caspase-9 [\#7237, CS, 1:1000], rabbit anti-PARP [\#9542, CS, 1:1000], rabbit anti-cleaved-PARP [\#5625, CS, 1:1000], rabbit anti-Beclin-1 [\#3495, CS, 1:1000]. Next, cells were washed with PBS (3 x 3 min) and incubated with FITC goat anti-mouse IgG [554001, B\&D, 1:1000] and anti-rabbit IgG [554020, B\&D, 1:1000] for $1 \mathrm{~h}$ in the dark at RT. Cells were washed with PBS ( $3 \times 3 \mathrm{~min}$ ) and incubated with Hoechst 33342 for 15 min. Samples were visualized with confocal laser scanning microscope BD Pathway 855 Bioimager (B\&D) using AttoVision software (B\&D).

\section{Concentration of proline}

Samples were analyzed by an HPLC system (1260 Infinity series, Agilent Technologies, Waldbronn, Germany) consisting of a degasser, binary pump, and thermostated autosampler maintained at $4^{\circ} \mathrm{C}$ connected to an Agilent Technologies QTOF (6530) mass spectrometry detector. Electrospray ionization (ESI) was used as an ion source in positive ionisation mode. Samples $(2 \mu \mathrm{L})$ were injected onto a HILIC column (Luna HILIC, 100x2.0mm; 3um; Phenomenex) thermostated at $40{ }^{\circ} \mathrm{C}$. The system was operated in positive and negative mode at flow rate $1 \mathrm{~mL} / \mathrm{min}$ with solvent $\mathrm{A}$ - water with $10 \mathrm{mM}$ ammonium formate $(70221$, Sigma-Aldrich) and solvent B - acetonitrile/ water (9:1, v:v) with 10mM ammonium formate. Mobile phase was $100 \%$ B during 1.5min in isocratic mode. The gradient started in 1.5 min from $100 \%$ B to $70 \%$ B in $5.5 \mathrm{~min}$, then $40 \% \mathrm{~B}$ in $6.0 \mathrm{~min}$, maintained $40 \% \mathrm{~B}$ during $1 \mathrm{~min}$ and returned to starting conditions in 0.5 $\mathrm{min}$, keeping the re-equilibration until $10 \mathrm{~min}$. The detector operated in full scan mode from 50 to 1000 $\mathrm{m} / \mathrm{z}$ with a scan rate of 1 scan per second. Accurate mass measurements were obtained by online mass correction to reference masses delivered continuously during analyses. Reference masses at m/z 121.0509 (protonated purine) and m/z 922.0098 [protonated hexakis $(1 \mathrm{H}, 1 \mathrm{H}, 3 \mathrm{H}$ tetrafluoropropoxy) phosphazine or HP-921]. The capillary voltage was set to $3000 \mathrm{~V}$, the gas temperature was $330^{\circ} \mathrm{C}$, the nebulizer gas flow rate was 10, $5 \mathrm{~L} / \mathrm{min}$. MS TOF parameters were as follows: fragmentor was set to $140 \mathrm{~V}$, skimmer $65 \mathrm{~V}$.

Quantitative analysis was performed monitoring monoisotopic ions of proline and the internal standard (Proline-d3) (791261, Sigma-Aldrich). Ions from isotopic distribution pattern were used as qualifiers. Calibration curve of proline was registered in concentration range: 6.32-101.12 $[\mu \mathrm{M}]$. Samples were analysed in triplicates and average value of signal was used for calculations. Calculated concentrations were normalized first to internal standard to correct ion suppression and then to the amount of protein in a sample.

\section{Statistical analysis}

Results are presented as mean values of six independent experiments \pm s.e.m. The statistical significance was calculated using one-way ANOVA with Dunnett's multiple comparison test with 95\% confidence interval in GraphPad PRISM v. 5 (GraphPad Software, Inc., California, USA). Results were considered significant at $* \mathrm{P}<0.01, * * \mathrm{P}<0,001$.

\section{Results}

Design and efficacy of shRNA-based PRODH/POX knock-down in MCF-7 cells

Proline dehydrogenase/proline oxidase (PRODH/POX) is encoded by the PRODH gene located on chromosome 22q11.21 and possesses two transcription variants. Designed shRNA constructs targeted exons 3 and 2 (PRODH shRNA1), exons 14 and 13 (PRODH shRNA2) and exons 15 and 14 (PRODH shRNA3) of transcription variant 1 and 2, respectively. Western blot protein analysis showed that the PRODH shRNA 2 construct was the most effective one in silencing PRODH/POX, decreasing its expression over 40\% of control MCF-7 cells (Fig. 1). This cell clone was named MCF-7shPRODH/POX and selected for further in vitro analysis. 


\section{Cellular Physiology Cell Physiol Biochem 2017;43:670-684 \begin{tabular}{l|l} 
and Biochemistry Publ: 10.1159/000480653 & $\begin{array}{l}\text { (c) } 2017 \text { The Author(s). Published by S. Karger AG, Basel } \\
\text { www.karger.com/cpb }\end{array}$
\end{tabular}

Fig. 1. Expression of PRODH/POX and $\beta$-actin in MCF-7 and MCF-7 ${ }^{\text {shPRODH/POX }}$ cells. Transfection of the MCF-7cells with different PRODH/ POX shRNA constructs (clone 1-3) were done. Fibroblasts were used as a negative control and colorectal cancer cells DLD-1, as positive control for the expression of PRODH/POX.

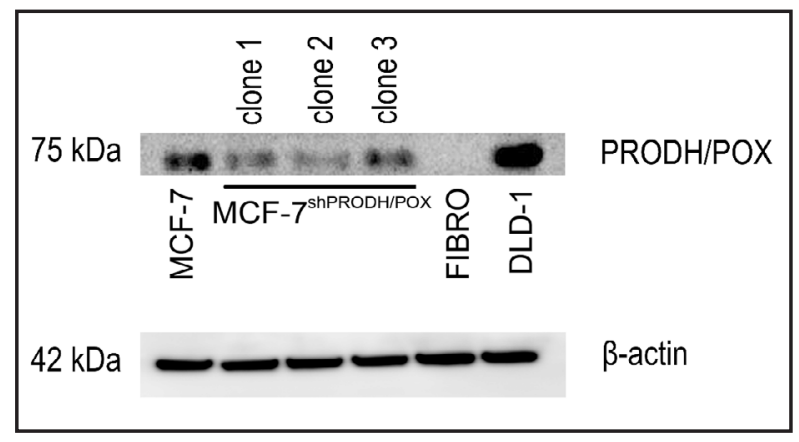

Fig. 2. Cell viability of MCF- $7^{\text {shProdh/POX }}$ versus MCF-7 cells, and the effect of A. rapamycin (Rap), B. 2-metoxyestradiol (MOE), C. glycyl-proline (GlyPro) and D. the combination of 2-metoxyestradiol and glycyl-proline (MOE+GlyPro) on the process. The mean values \pm SEM from 3 experiments done in duplicates are presented. Asterisks indicate differences between studied cells compared to control untreated MCF-7 cells as well as between treated MCF-7 and MCF-7 $7^{\text {shPRODH/ }}$ Pox cells at ${ }^{*} \mathrm{P}<0.01 ;{ }^{* *} \mathrm{P}<0.001$.

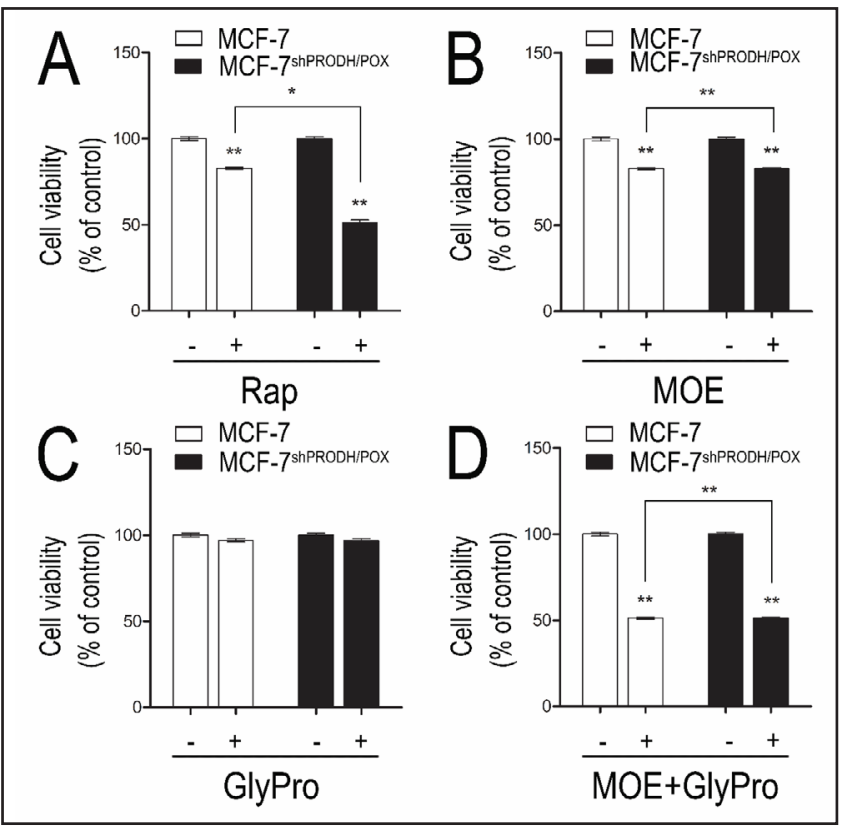

Effect of inhibition of proline utilization on cell viability, DNA and collagen synthesis and prolidase activity in MCF-7 ${ }^{\text {shPRODH/POX }}$ cells

There was no significant difference in cell viability between MCF-7 ${ }^{\text {shPRODH/POX }}$ and MCF-7 control cells (Fig. 2). Rap, MOE or combination of MOE+GlyPro decreased viability of MCF-7 and MCF-7 ${ }^{\text {shPRODH} / P O x}$ cells compared to untreated control MCF-7 cells (Fig. 2A, B, D), while GlyPro alone had no effect on cell viability (Fig. 2C). We also confirmed cell viability by MTT Cell Proliferation Assay (data not shown).

Basal DNA biosynthesis was decreased in MCF-7 ${ }^{\text {shPRODH/POx }}$ compared to MCF-7 cells (Fig. 3). DNA biosynthesis was further decreased by Rap, MOE and combination of MOE+GlyPro stimulation in both cell lines (Fig. 3A, B, D), but GlyPro did not affect the process in MCF-7 cells and decreased it only in MCF-7 ${ }^{\text {shPRoDH/POX }}$ cells (Fig. 3C). The data is supported by the growth cells curve and viability (data not shown).

PRODH/POX silencing significantly decreased collagen biosynthesis in MCF-7 cells (Fig. 4). Rap, MOE or combination of MOE+GlyPro decreased collagen biosynthesis in both cell lines (Fig 4A, B, D). However, GlyPro alone increased collagen biosynthesis in MCF-7 cells, while in MCF-7 ${ }^{\text {shPRODH/POx }}$ cells it decreased the process compared to control cells (Fig. 4C).

Prolidase activity was increased in both stimulated and non-stimulated MCF-7 $7^{\text {shPRODH/POX }}$ cells, compared to MCF-7 cells. However, all studied compounds, except MOE+GlyPro inhibited prolidase activity in MCF- $7^{\text {shPRODH/POX }}$ cells compared to untreated MCF-7 ${ }^{\text {shPRODH/POX }}$ cells (Fig. 5A-D). In MCF-7 cells, the compounds differently affected prolidase activity; Rap inhibited, while GlyPro and MOE+GlyPro stimulated the enzyme activity (Fig. 5). 
Fig. 3. Proliferation of MCF$7^{\text {shPRoDH/POX }}$ versus MCF-7 cells, and the effect of A. rapamycin (Rap), B. 2-metoxyestradiol (MOE), C. glycyl-proline (GlyPro) and D. the combination of 2-metoxyestradiol and glycyl-proline (MOE+GlyPro) on the process. The mean values \pm SEM from 3 experiments done in duplicates are presented. Asterisks indicate differences between studied cells compared to control untreated MCF-7 cells as well as between treated MCF-7 and MCF$7^{\text {shPRodh } / \mathrm{POX}}$ cells at $* \mathrm{P}<0.01$; ** $\mathrm{P}<0.001$.

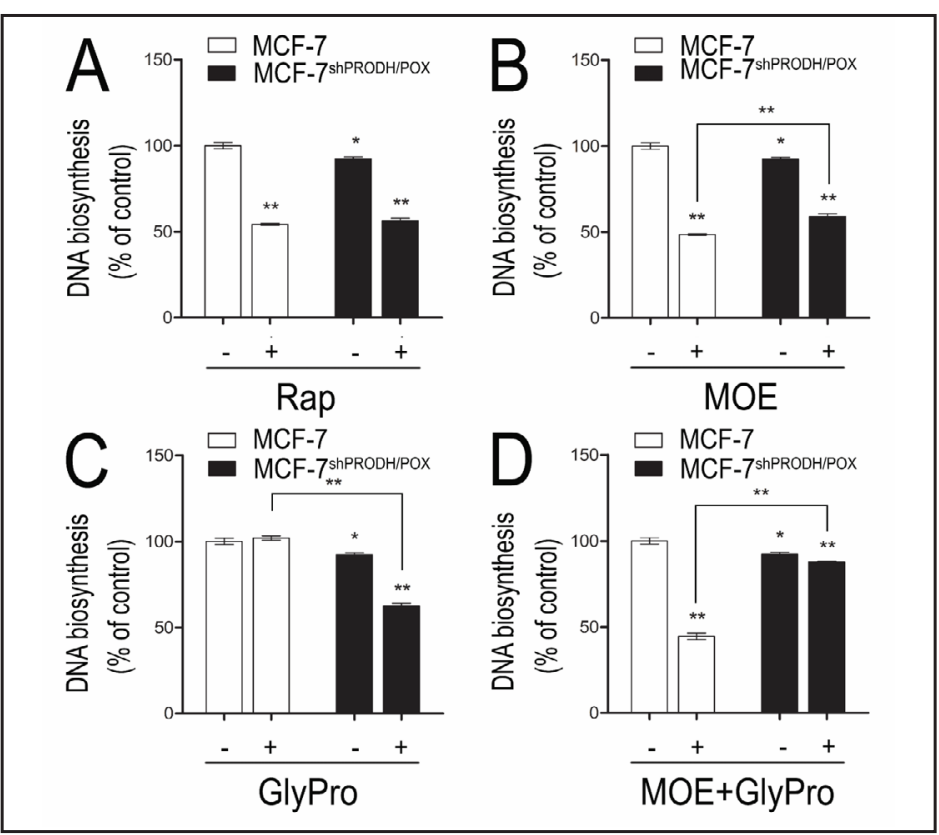

Fig. 4. Collagen biosynthesis in

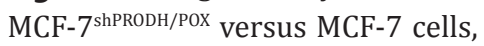
and the effect of A. rapamycin (Rap), B. 2-metoxyestradiol (MOE), C. glycyl-proline (GlyPro) and D. the combination of 2-metoxyestradiol and glycyl-proline (MOE+GlyPro) on the process. The mean values \pm SEM from 3 experiments done in duplicates are presented. Asterisks indicate differences between studied cells compared to control untreated MCF-7 cells as well as between treated MCF-7 and MCF$7^{\text {shPRODH/POX }}$ cells at $* \mathrm{P}<0.01$; ** $\mathrm{P}<0.001$.

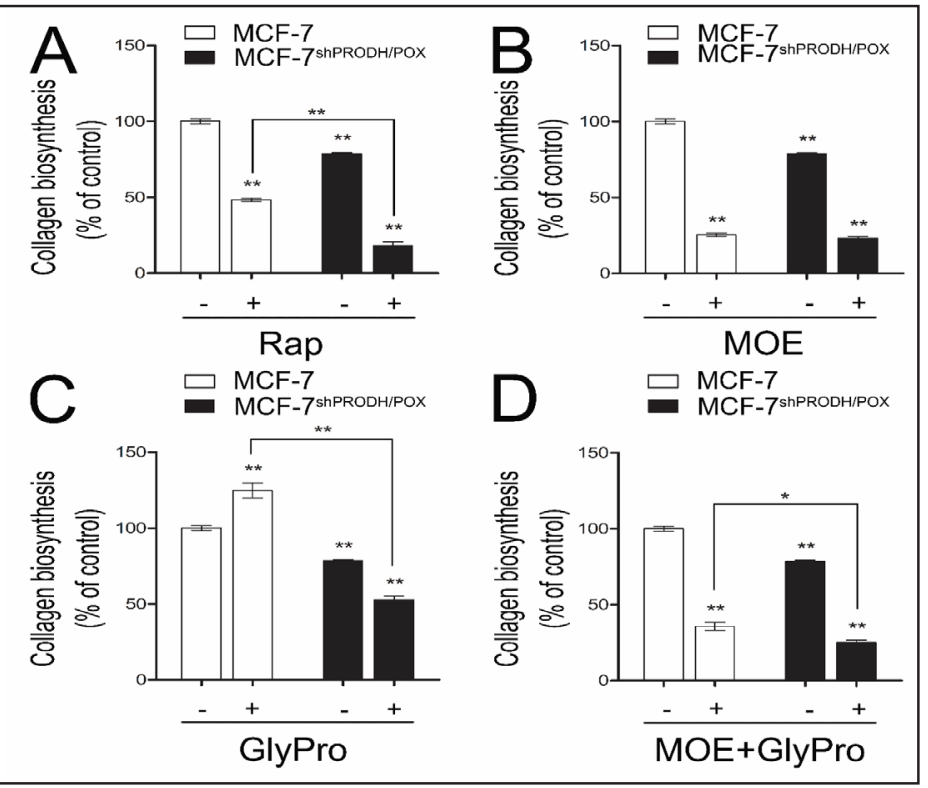

Inhibition of proline utilization induces PRODH/POX-dependent apoptosis

To evaluate effectiveness of PRODH/POX silencing we analyzed the enzyme expression in designed experimental conditions. Treatment of MCF-7 cells with Rap, MOE, GlyPro or combination of MOE+GlyPro upregulated expression of PRODH/POX, while in MCF-7 ${ }^{\text {shPRODH/POX }}$ cells the enzyme expression was non-detectable (Fig. 6).

To test the role of proline in regulation of PRODH/POX-dependent apoptosis or survival we analyzed the effect of Rap, MOE, GlyPro and MOE+GlyPro on expression of p53, cleaved and non-cleaved caspase- 3 , caspase- 9 and PARP, beclin-1, atg7, HIF- $1 \alpha$ and NF- $\mathrm{KB}$ in MCF-7 and MCF-7 $7^{\text {shPRODH/POX }}$ cells by Western blotting. Expression of beclin-1, atg7 and HIF$1 \alpha$ proteins were upregulated in MCF-7 ${ }^{\text {shPRODH/POX }}$ compared to MCF-7 cells (Fig. 6). In cells with lower expression of PRODH/POX the expression of beclin-1 was higher than in MCF-7 cells. However, in MCF-7 cells, MOE decreased the level of beclin-1 expression. Expression of atg7 was increased in treated and untreated MCF- $7^{\text {shPRODH/POX }}$ cells, while in MCF-7 cells only 


\section{\begin{tabular}{ll} 
Cellular Physiology & Cell Physiol Biochem 2017;43:670-684 \\
\hline DOI: 10.1159/000480653 & 2017 The Author(s). Published by S. Karger AG, Basel
\end{tabular}

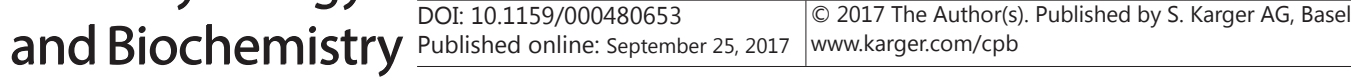 \\ Zareba et al.: A Viable Functional In Vitro Model for Proline Oxidase Research}

Fig. 5. Prolidase activity in MCF$7^{\text {shPRODH/POX }}$ versus MCF-7 cells, and the effect of $A$. rapamycin (Rap), B. 2-metoxyestradiol (MOE), C. glycyl-proline (GlyPro) and D. the combination of 2-metoxyestradiol and glycyl-proline (MOE+GlyPro) on the process. The mean values \pm SEM from 3 experiments done in duplicates are presented. Asterisks indicate differences between studied cells compared to control untreated MCF-7 cells as well as between treated MCF-7 and MCF$7^{\text {shPRODH } / \mathrm{POX}}$ cells at $* \mathrm{P}<0.01$; ** $\mathrm{P}<0.001$.
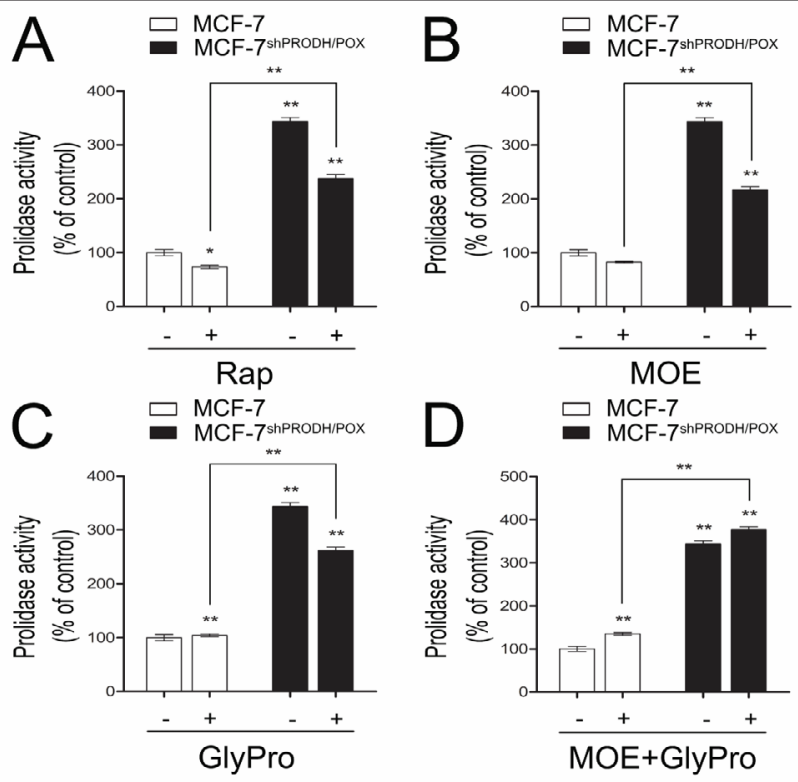

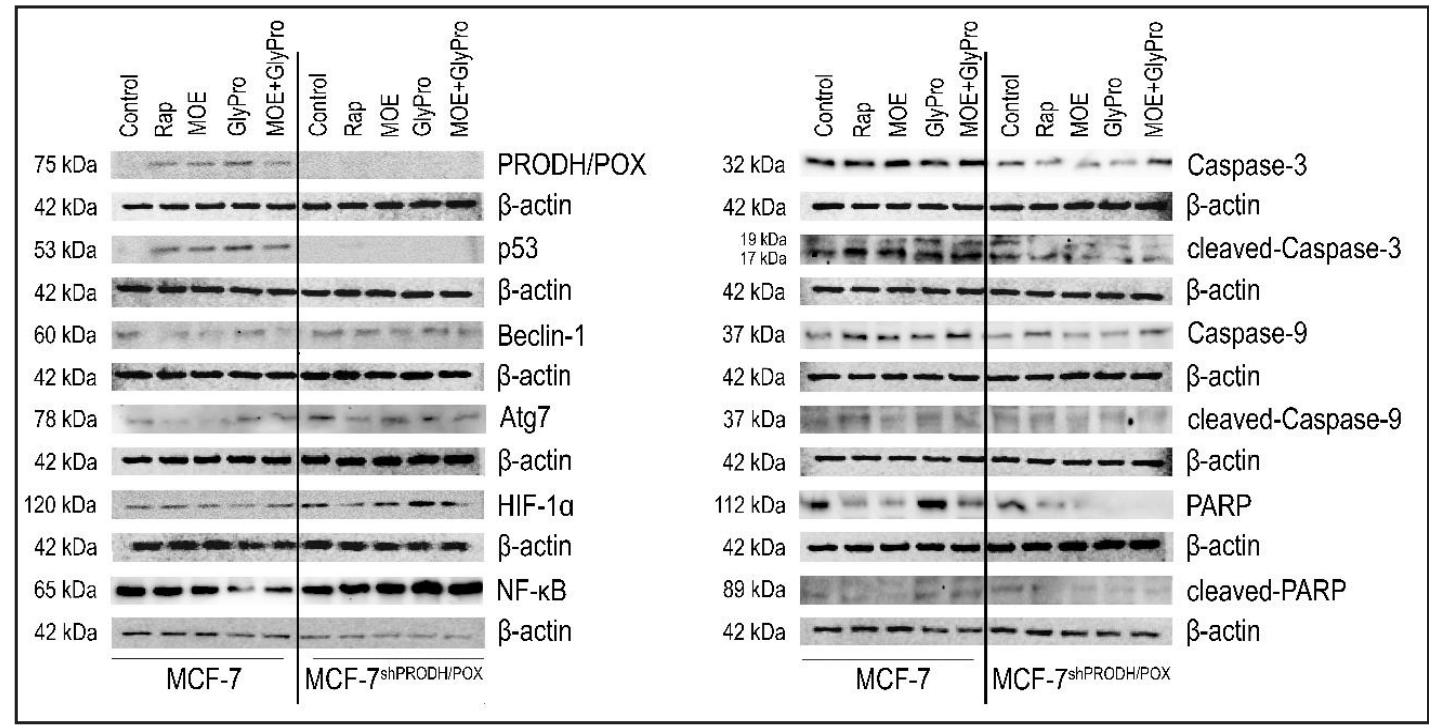

Fig. 6. Expression of PRODH/POX, p53, un-cleaved caspase-3, cleaved-caspase-3, un-cleaved caspase-9, cleaved-caspase-9, un-cleaved PARP, cleaved-PARP, beclin-1, atg7, HIF- $1 \alpha$, NF- $\kappa$ B and $\beta$-actin in MCF-7 ${ }^{\text {shPRODH/ }}$ Pox versusMCF-7 cells and the effect of rapamycin (Rap), 2-metoxyestradiol (MOE), glycyl-proline (GlyPro) and the combination of 2-metoxyestradiol and glycyl-proline (MOE+GlyPro) on the process. The mean values of 6 pooled cell homogenates extracts from 3 independent experiments are presented. $\beta$-actin was used as a control.

GlyPro and combination MOE+GlyPro increased expression of this protein. In MCF-7 cells MOE and GlyPro decreased expression of HIF-1 $\alpha$, while Rap and MOE+GlyPro had no effect

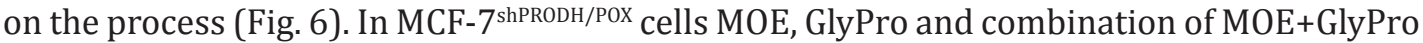
upregulated HIF-1 $\alpha$ expression, while Rap down-regulated the process, compared to control (Fig. 6).

In MCF-7 cells treated with Rap, MOE, GlyPro and MOE+GlyPro expression of NF- $\kappa B$ was decreased, while in MCF-7 $7^{\text {shPRODH/POX }}$ cells the compounds increased the expression of this transcription factor. 


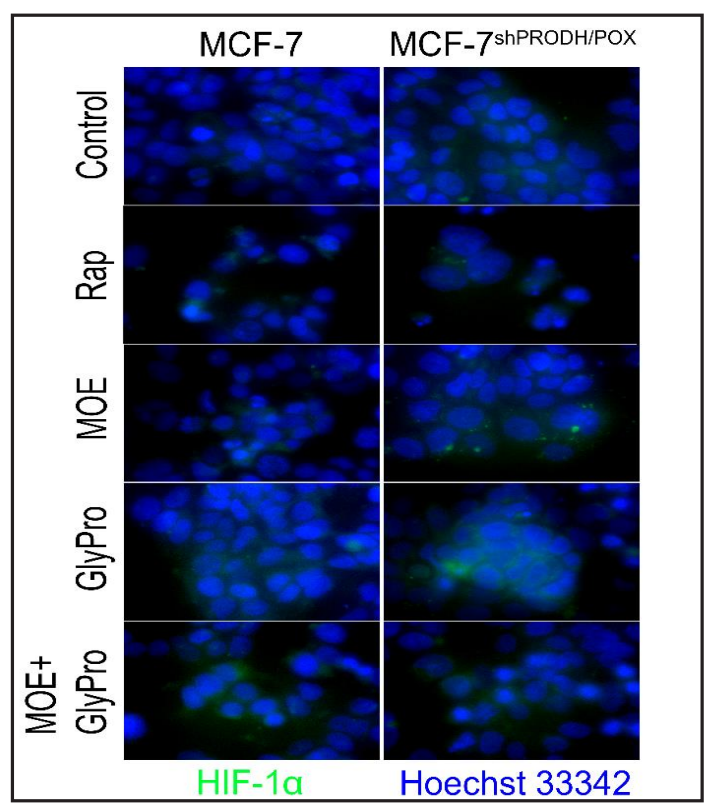

Fig. 7. Immunofluorescence analysis of HIF-1 $\alpha$ in

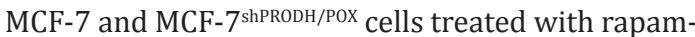
ycin (Rap), 2-metoxyestradiol (MOE), glycyl-proline (GlyPro) and the combination of 2-metoxyestradiol and glycyl-proline (MOE+GlyPro).

Expression of p53, cleaved and uncleaved caspase-3, caspase- 9 and PARP were increased in treated MCF-7 cells, compared to MCF-7 $7^{\text {shPRODH/POX }}$ cells (Fig 6).

We further confirmed our data by immunofluorescence bio-imaging (Fig. 7, 8 and 9). HIF-1 $\alpha$, beclin-1, cleaved and un-cleaved caspase- 3 and caspase- 9 were detected by FITC-labelled specific antibodies. The cells were stained with Hoechst 33321 to visualize cell nucleus. Expression of HIF-1 $\alpha$ and beclin-1 were upregulated in MCF-7 shPRODH/ $^{\text {s. }}$ Pox cells, especially when treated with MOE, GlyPro and combination of MOE+GlyPro, compared to MCF-7 cells (Fig. 7; Fig. 8). Expression of un-cleaved caspase-3 were upregulated in treated and untreated MCF-7 and MCF-7 ${ }^{\text {shPRODH/POX }}$ cells (Fig. 9), while expression of cleaved-caspase-3 was up-regulated only in MCF-7 cells (Fig. 10). Expression of un-cleaved caspase- 9 was upregulated in MCF-7 cells treated with MOE and GlyPro and in treated and untreated MCF$7^{\text {shPRODH/POX }}$ cells (Fig .11), while the expression of cleaved-caspase- 9 was up-regulated in treated MCF-7 and only in Rap treated MCF-7 ${ }^{\text {shPRODH/POX }}$ cells (Fig. 12).

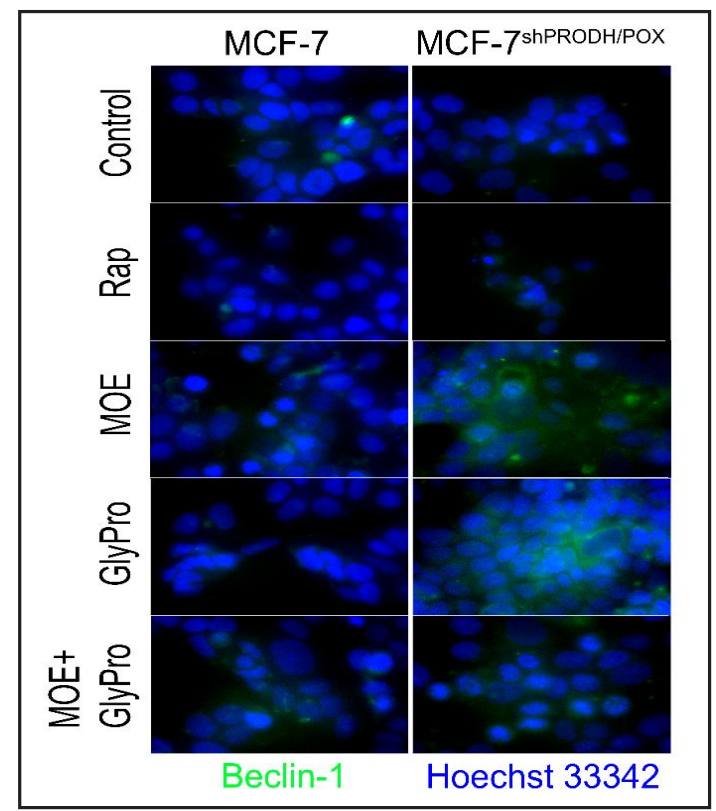

Fig. 8. Immunofluorescence analysis of beclin-1 in

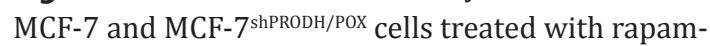
ycin (Rap), 2-metoxyestradiol (MOE), glycyl-proline (GlyPro) and the combination of 2-metoxyestradiol and glycyl-proline (MOE+GlyPro).

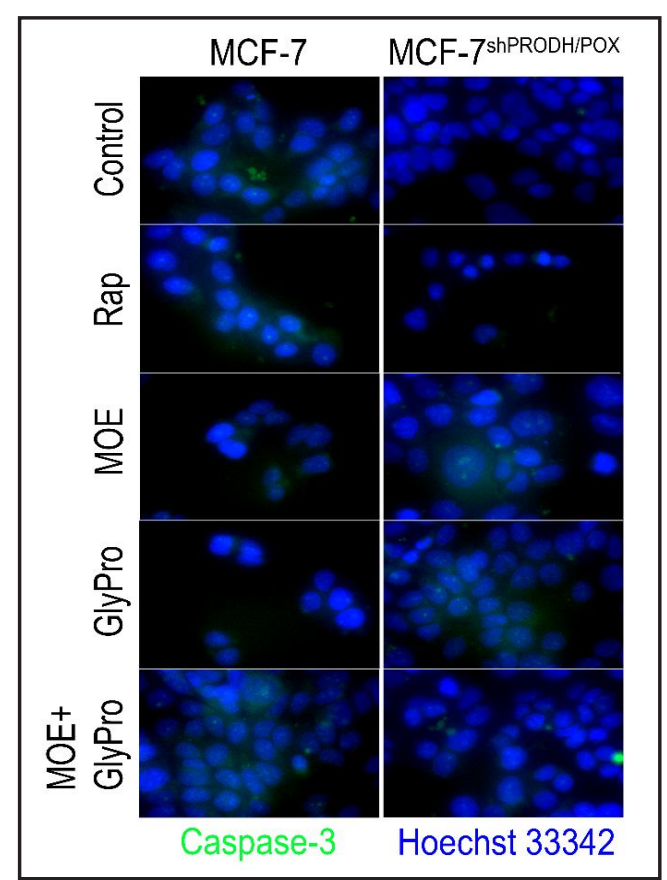

Fig. 9. Immunofluorescence analysis of un-cleaved caspase-3 in MCF-7 and MCF-7 ${ }^{\text {shPRODH/POx }}$ cells treated with rapamycin (Rap), 2-metoxyestradiol (MOE), and glycyl-proline (GlyPro) and the combination of 2-metoxyestradiol and glycyl-proline (MOE+GlyPro). 


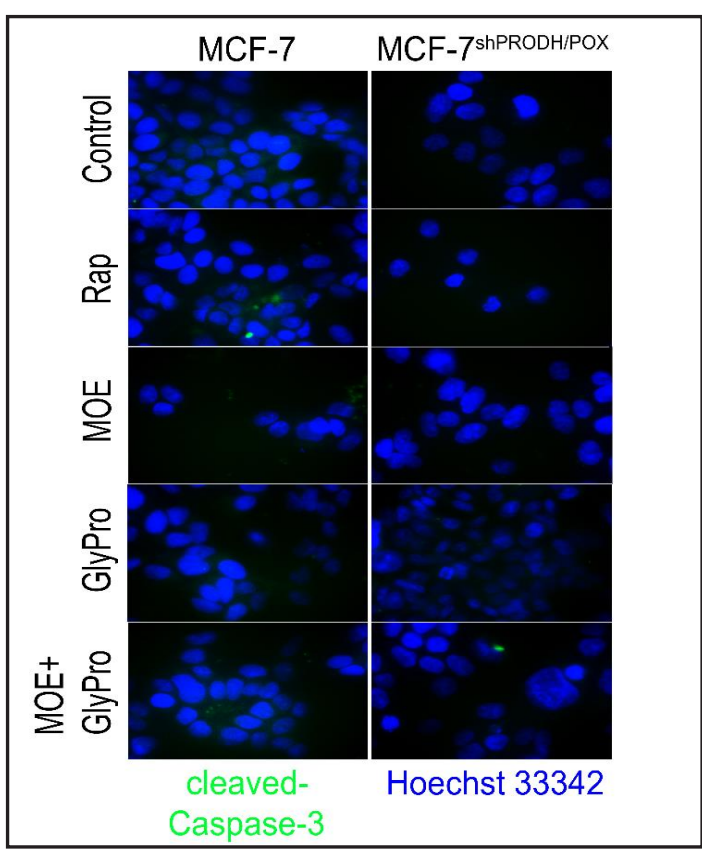

Fig. 10. Immunofluorescence analysis of cleavedcaspase-3 in MCF-7 and MCF-7 ${ }^{\text {shPRODH/POX }}$ cells treated with rapamycin (Rap), 2-metoxyestradiol (MOE), and glycyl-proline (GlyPro) and the combination of 2-metoxyestradiol and glycyl-proline (MOE+GlyPro).

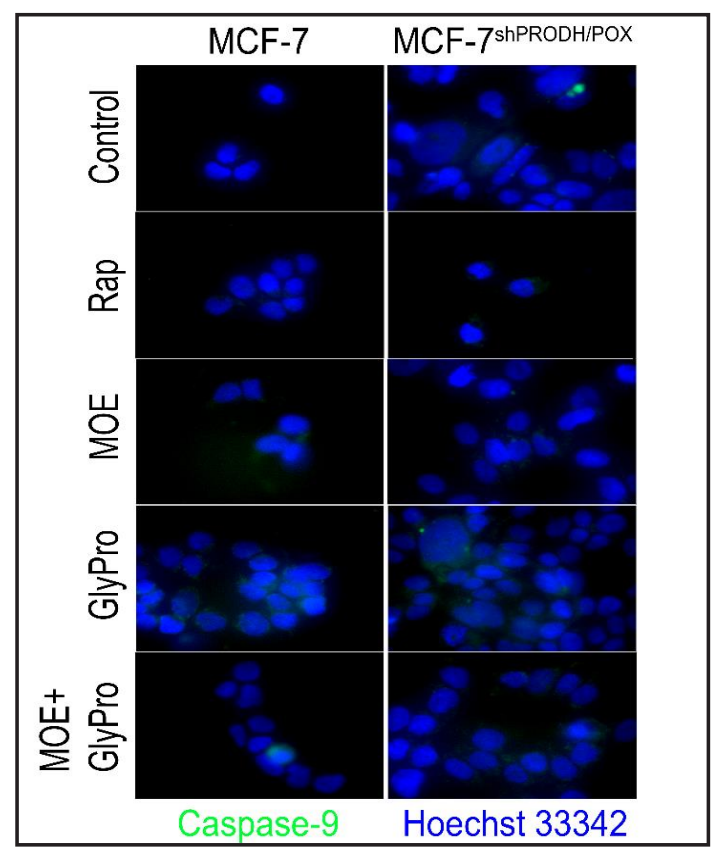

Fig. 11. Immunofluorescence analysis of un-cleaved caspase-9 in MCF-7 and MCF-7 shPRODH/POX $^{\text {cells treated }}$ with rapamycin (Rap), 2-metoxyestradiol (MOE), and glycyl-proline (GlyPro) and the combination of 2-metoxyestradiol and glycyl-proline (MOE+GlyPro).

\section{Effect of inhibition of proline utilization on proline concentration in MCF-7 shPRODH/ $^{-1}$ POX cells}

There was a significant increase in proline concentration in MCF-7 ${ }^{\text {shPRODH/POX }}$ compared to MCF-7 control cells (Fig. 13). Proline concentration further increased in both cell lines after stimulation by MOE, GlyPro and combination of MOE+GlyPro, compared to untreated MCF-7 cells (Fig. 13).

\section{Discussion}

Although the functional significance of proline catabolism by PRODH/POX is well recognized $[13,15,23,24]$ the mechanism of PRODH/POX-dependent apoptosis and autophagy is poorly understood. Here we provide evidence that PRODH/POX silencing contributes to induction of pro-survival pathways in MCF-7 cells. We knocked-down significantly PRODH/POX expression and created constitutively silenced cell line on the basis of MCF-7 cells, which induced functional phenotypic changes. We were not able

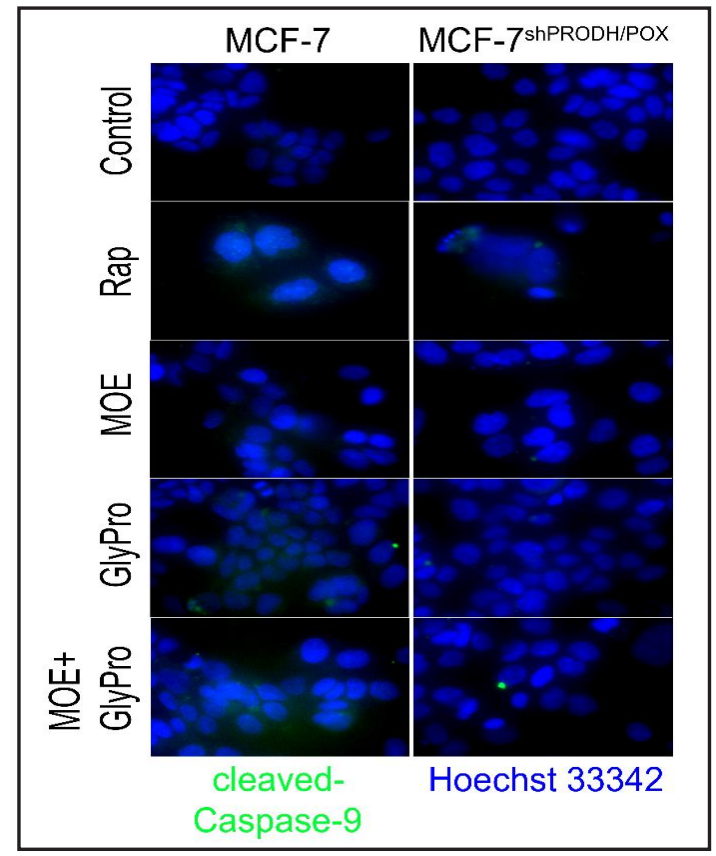

Fig. 12. Immunofluorescence analysis of cleavedcaspase-9 in MCF-7 and MCF-7 shPRoDH/Pox $^{\text {cells treated }}$ with rapamycin (Rap), 2-metoxyestradiol (MOE), and glycyl-proline (GlyPro) and the combination of 2-metoxyestradiol and glycyl-proline (MOE+GlyPro).

\section{KARGER}




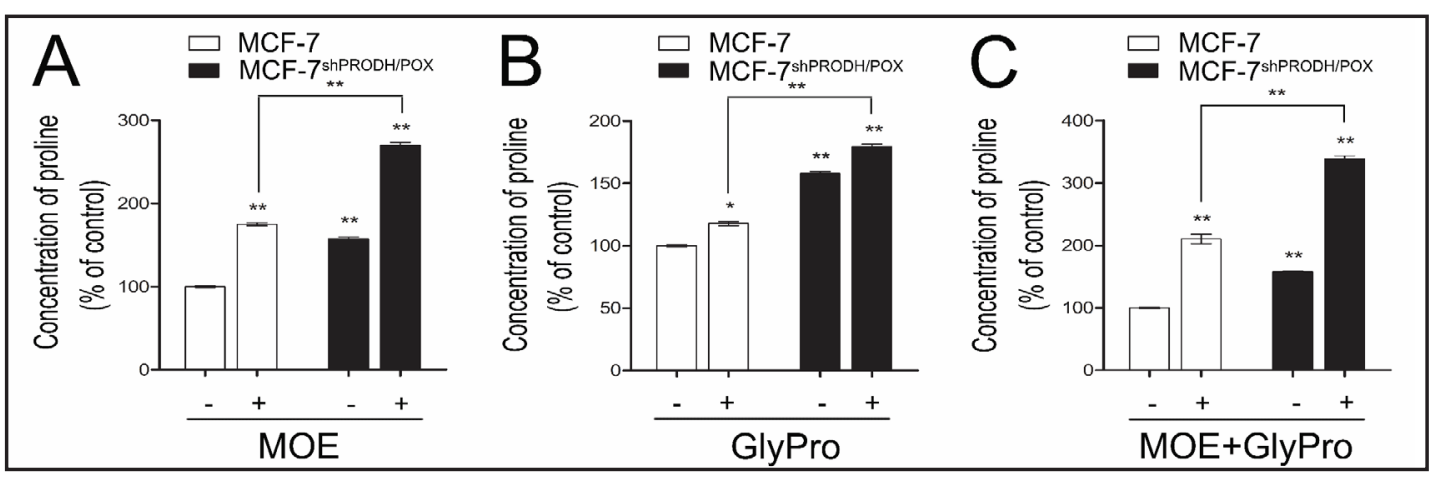

Fig. 13. Proline concentration in MCF-7 $7^{\text {shPRoDH/Pox }}$ versus MCF-7 cells, and the effect of A. 2-metoxyestradiol (MOE), B. glycyl-proline (GlyPro) and C. the combination of 2-metoxyestradiol and glycyl-proline (MOE+GlyPro) treatment on intracellular proline concentration. The mean values \pm SEM from 3 experiments done in duplicates are presented. Asterisks indicate differences between studied cells compared to control untreated MCF-7 cells as well as between treated MCF-7 and MCF-7 ${ }^{\text {shPRODH} / \mathrm{POx}}$ cells at ${ }^{*} \mathrm{P}<0.01 ;{ }^{* *} \mathrm{P}<0.001$.

to achieve a complete $(<90 \%)$ knock-down of PRODH/POX in MCF-7 cells due to a technical aspect of the experiment. However, both MCF-7 ${ }^{\text {shPRODH/POX }}$ and MCF-7 cells transfected with empty vector evoked similar growth curve to wild-type of MCF-7 cells during time course of experiment (data not shown). We also confirmed that PRODH/POX silencing does not affect cell viability and cell proliferation (data not shown).

PRODH/POX silencing in MCF-7 cells decreased DNA and collagen biosynthesis and increased prolidase activity. A plausible explanation of this phenomenon could be that the increase in the proline level in cytoplasm occurred as a result of decreased PRODH/POX expression. Proline and its metabolism play an important role in the proper functioning of the cell [4]. Proline is known to act as a stress signalling molecule in mitochondria [11, 22, 25] and cytoplasm $[4,7,23,24]$. Proline bearing reducing potential must be converted in mitochondria to P5C by PRODH/POX for regeneration of oxidizing potential. On the other hand, $\mathrm{P} 5 \mathrm{C}$ is converted in cytoplasm to proline by $\mathrm{P} 5 \mathrm{C}$ reductase. The interconversion is known as a "proline cycle" (conversion of proline-P5C in mitochondria by PRODH/POX and P5Cproline in cytosol by $\mathrm{P} 5 \mathrm{C}$-reductase) that transfers reducing and oxidizing potential between mitochondria and cytosol using NAPDH/NADP ${ }^{+}[23,24]$. This shuttle is coupled to glycolisys and pentose phosphate pathway that supports biosynthesis of pyridine nucleotides [10]. Therefore, down-regulation of PRODH/POX may affect DNA biosynthesis and cell proliferation.

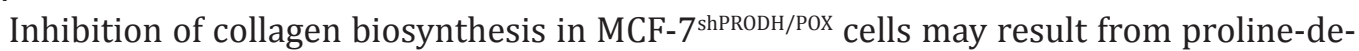
pendent inhibition of prolyl hydroxylase [4]. Prolyl hydroxylase is a key enzyme, required for triple helical structure of collagen during its biosynthesis [23]. Free proline has been shown to inhibit prolyl hydroxylase [4], suggesting a mechanism for proline-dependent attenuation of collagen biosynthesis. Although, we do not know what could be the mechanism of increased prolidase activity in MCF-7 ${ }^{\text {shPRODH/POX }}$ compared to MCF-7 cells, this process could lead to proline accumulation in MCF- $7^{\text {shPRODH/POX }}$ cells. We hypothesized that proline availability for PRODH/POX-dependent functions is regulated by prolidase activity, while utilization of proline by collagen biosynthesis. Therefore, we used several compounds that affect cytoplasmic pool of proline. We used 2-metoxyestradiol (MOE) as an inhibitor of HIF-1 $\alpha$ and collagen biosynthesis while rapamycin (Rap) to inhibit mTOR and prolidase activity. In order to increase cytoplasmic level of proline, glycyl-proline (GlyPro) was used as a substrate for prolidase. Although the mechanism by which the studied compounds upregulate PRODH/ POX is unknown, the possible explanation comes from studies of Krishnan et al., showing that there is a tide correlation between cytoplasmic proline level and mitochondrial PRODH/ POX activity [26]. 


\section{Cellular Physiology Cell Physiol Biochem 2017;43:670-684 \begin{tabular}{ll|l} 
and Biochemistry Published online: September 25, 2017 & $\begin{array}{l}\text { (c) } 2017 \text { The Author(s). Published by S. Karger AG, Basel } \\
\text { www.karger.com/cpb }\end{array}$ \\
\hline
\end{tabular} \\ Zareba et al.: A Viable Functional In Vitro Model for Proline Oxidase Research}

Rap (inhibitor of prolidase activity and mTOR signaling) treatment of MCF-7 shPRODH/POX $^{\text {POP }}$ cells further decreased cell viability, DNA and collagen biosynthesis, while prolidase activity (despite Rap-dependent inhibition) was still very high, compared to MCF-7 cells. Since Rap inhibits proliferation of normal [27] and cancer [28] cells, the growth-inhibiting activity of

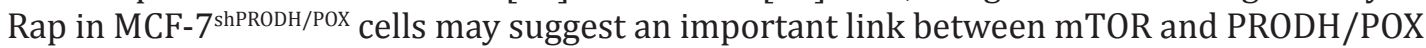
in regulation of cell growth. In fact, Rap was found to activate PRODH/POX [29] resulting in an inhibition of cell proliferation. Regarding collagen biosynthesis, Rap was found to inhibit collagen production [30].

MOE (an inhibitor of collagen biosynthesis and HIF-1 $\alpha$ transcriptional activity) decreased cell viability, DNA and collagen biosynthesis similarly in MCF-7 and MCF-7 ${ }^{\text {shPRoDH/ }}$ Pox cells. However, prolidase activity (despite MOE-dependent inhibition) was maintained very high in MCF-7 ${ }^{\text {shPRODH/POX }}$ compared to MCF-7 cells. Increase in prolidase activity in these cells was accompanied by an increase in proline levels in cytoplasm. It is well recognized that MOE induces mitotic arrest and apoptosis in carcinoma cells [31]. However, in ovarian carcinoma cells lacking PRODH/POX [32], on the contrary, MOE stimulated cell proliferation [33]. The discrepancy may suggest that the underlying mechanism of this phenomenon could involve other factors than the proline availability and PRODH/POX activity. The inhibition of cell proliferation in MCF- $7^{\text {shPRODH/POX }}$ is likely to be associated with modulation of cell signaling pathways and cell cycle regulatory processes, because it was found modulation of EGFR, COX-2 and MAPK signaling Wnt/ $\beta$-catenin pathway by PRODH/POX [34, 35].

GlyPro, a substrate for prolidase further decreased DNA and collagen biosynthesis, however, prolidase activity (despite GlyPro-dependent inhibition) was still very high in MCF$7^{\text {shPRODH/POX }}$ cells, compared to MCF-7 cells. Considering that GlyPro provides substrate for proline generation, the decrease in above mentioned processes is most likely a consequence of proline accumulation in the cell. In fact, in GlyPro-treated cells, intracellular proline was significantly increased. High level of proline due to GlyPro stimulation and its impaired conversion into $\mathrm{P} 5 \mathrm{C}$ in MCF- $7^{\text {shPRODH/POX }}$ cells could impair the regeneration of oxidizing potential, resulting in an attenuation of DNA and protein synthesis [36, 37]. The collagen biosynthesis

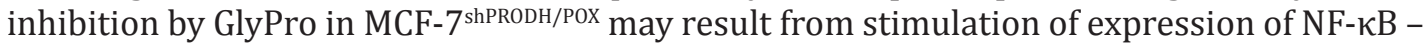
inhibitor of collagen gene expression [38]. Inhibition of prolidase activity by GlyPro in MCF$7^{\text {shPRODH/POX }}$ cells could result from the substrate inhibition [39].

Although cell viability was similar in MCF-7 and MCF-7 ${ }^{\text {shPRODH/POx }}$ cells, MOE+GlyPro treatment significantly decreased cell viability in both cell lines. In respect to DNA biosynthesis, MOE+GlyPro significantly inhibited this process only in MCF-7 cells. It shows that simultaneous inhibition of proline utilization for collagen biosynthesis and providing substrate for proline generation may attenuate proliferation only in MCF-7 cells, expressing PRODH/POX. The functional significance of simultaneous inhibition of proline utilization and stimulation of proline generation was shown by Western blot and confocal microscopy bioimaging for cleaved and un-cleaved caspase- 3 and -9 .

Our data suggest that proline availability and PRODH/POX expression are required for induction of apoptosis as detected by expression of cleaved caspases-3, caspase-9 and PARP in MCF-7 cells. Several environmental conditions, such as hypoxia and nutrient stress are known to upregulate PRODH/POX expression [13, 40]. Interestingly, in response to stress signals, PRODH/POX expression is up-regulated by tumor suppressor p53 [41]. In fact, we found that $\mathrm{p} 53$ was expressed only in PRODH/POX expressing MCF-7 cells treated with MOE and GlyPro that increased cytoplasmic level of proline.

mTOR pathway is dependent on the availability of nutrients $[24,42]$. Inhibition of mTOR by Rap and/or by glucose deprivation upregulates PRODH/POX expression [13, 24, 29]. Although, many factors may play a role in the regulation of PRODH/POX and apoptosis/survival $[1,43,44]$, data presented in this report suggest that the key role in switching into apoptotic mode may play massive proline utilization in mitochondria by PRODH/POX. Such a situation may take place when cytoplasmic level of proline is high. The main factor responsible for increase in proline concentration is prolidase $[45,46]$. However, proline is quickly utilized in the process of collagen biosynthesis in order to remove the reducing potential of proline 


\section{Cellular Physiology Cell Physiol Biochem 2017;43:670-684 \begin{tabular}{c|c|c|} 
DOI: 10.1159/000480653 & O 2017 The Author(s). Published by S. Karger AG, Basel \\
wwww.karger.com/cpb
\end{tabular} \\ Zareba et al.: A Viable Functional In Vitro Model for Proline Oxidase Research}

from metabolic pool and maintain redox balance [46]. Therefore, when collagen biosynthesis is blocked and prolidase is active, proline accumulate in cytoplasm, enters mitochondria and is converted into P5C, yielding ROS-induced apoptosis. Such a hypothesis is supported by our data showing that in MCF-7 cells MOE as well as MOE+GlyPro induced expression of cleaved caspases-3 and -9 more effectively then in MCF-7 ${ }^{\text {shPRODH/POX }}$ cells.

On the other hand, autophagy markers (e.g. beclin-1, Atg7, HIF-1 $\alpha$ ) were up-regulated in

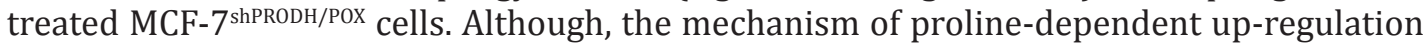
of proteins reflecting autophagy is unknown, the mechanism of proline-dependent up-regulation of HIF- $1 \alpha$ transcriptional activity is well recognized.

Proline, by inhibition of HIF prolyl hydroxylase activity [4] suppresses proteosomal degradation of HIF- $1 \alpha$ and increases HIF- $1 \alpha$ transcriptional activity $[4,7,47]$. Therefore, increase in cytoplasmic proline concentration, which mostly depends on prolidase activity, contributes to increase in HIF- $1 \alpha$ transcriptional activity [4]. HIF- $1 \alpha$ by targeting pro-inflammatory and pro-angiogenic genes (e.g. COX-2, VEGF, TNF- $\alpha$, IL-1, NF-kB) promote pro-survival signalling pathways [48]. Interestingly, HIF-1 $\alpha$ was also found to play a regulatory role in hydroxylation and secretion of collagen [49] suggesting another modulatory mechanism of collagen production. We provided evidence that expression of HIF-1 $\alpha$ was more pronounced in MCF-7 ${ }^{\text {shPRODH/POX }}$ cells than in MCF-7 cells, suggesting pro-survival mode of the cells.

In this study, we found that the inhibition of proline utilization in collagen biosynthesis or stimulation of its accumulation enhanced PRODH/POX-dependent pro-apoptotic pathways in MCF-7 human breast cancer cells. However, the role of specific metabolites of proline interconversion in the mechanism that leads to apoptosis or autophagy remains unknown. Large amount of proline is also derived from glutamine that is linked to the tumor metabolism $[10,12,50,51]$. Therefore, the identification of specific pathway of proline metabolism that is involved in regulation of apoptosis/survival is of particular importance and requires further studies. Furthermore, we had been able to establish and characterize a constitutively downregulated PRODH/POX MCF-7 cell line (MCF-7shPRODH/POX) that may serve as a model for studying proline utilization or generation in PRODH/POX-dependent pro-apoptotic pathway.

\section{Acknowledgements}

This work was supported by the National Science Center (number of project: 2014/13/B/ NZ7/02196). Ilona Zareba was supported by funds from Leading National Research Center at Medical University of Bialystok. The sequences used to silence PRODH/POX expression in cells were subject for patent application (patent application number: P.421954).

\section{Disclosure Statement}

The authors declare that they have no conflicts of interest.

\section{References}

1 Catchpole G, Platzer A, Weikert C, Kempkensteffen C, Johannsen M, Krause H, Jung K, Miller K, Willmitzer L, Selbig J, Weikert S: Metabolic profiling reveals key metabolic features of renal cell carcinoma. J Cell Mol Med 2011;15:109-118.

- Hirayama A, Kami K, Sugimoto M, Sugawara M, Toki N, Onozuka H, Kinoshita T, Saito N, Ochiai A, Tomita M, Esumi H, Soga T: Quantitative metabolome profiling of colon and stomach cancer microenvironment by capillary electrophoresis time-of-flight mass spectrometry. Cancer Res 2009;69:4918-4925.

-3 Ii M, Yamamoto H, Adachi Y, Maruyama Y, Shinomura Y: Role of matrix metalloproteinase-7 (matrylisin) in human cancer invasion, apoptosis, growth, and angiogenesis. Exp Biol Med 2006, pp 20-27. 


\section{Cellular Physiology Cell Physiol Biochem 2017;43:670-684 \begin{tabular}{l|l|l} 
DOI: 10.1159/000480653 & O 2017 The Author(s). Published by S. Karger AG, Basel \\
wwww.karger.com/cpb
\end{tabular}

4 Surazynski A, Donald SP, Cooper SK, Whiteside MA, Salnikow K, Liu Y, Phang JM: Extracellular matrix and HIF-1 signaling: the role of prolidase. Int J Cancer 2008;122:1435-1440.

5 Palka JA, Phang JM: Prolidase activity in fibroblasts is regulated by interaction of extracellular matrix with cell surface integrin receptors. J Cell Biochem 1997;67:166-175.

6 Surazynski A, Miltyk W, Palka J, Phang JM: Prolidase-dependent regulation of collagen biosynthesis. Amino Acids 2008;35:731-738.

7 Jaakkola P, Mole DR, Tian YM, Wilson MI, Gielbert J, Gaskell SJ, von Kriegsheim A, Hebestreit HF, Mukherji M, Schofield CJ, Maxwell PH, Pugh CW, Ratcliffe PJ: Targeting of HIF-alpha to the von Hippel-Lindau ubiquitylation complex by 02-regulated prolyl hydroxylation. Science 2001;292:468-472.

-8 Jackson SH, Heininger JA: A reassessment of the collagen reutilization theory by an isotope ratio method. Clin Chim Acta 1973;46:153-160.

-9 Jackson SH, Dennis AW, Greenberg M: Iminodipeptiduria: a genetic defect in recycling collagen; a method for determining prolidase in erythrocytes. Can Med Assoc J 1975;113:759, 762-753.

10 Liu W, Hancock CN, Fischer JW, Harman M, Phang JM: Proline biosynthesis augments tumor cell growth and aerobic glycolysis: involvement of pyridine nucleotides. Sci Rep 2015;5:17206.

11 Phang JM, Liu W, Zabirnyk O: Proline metabolism and microenvironmental stress. Annu Rev Nutr 2010;30:441-463.

12 Phang JM, Donald SP, Pandhare J, Liu Y: The metabolism of proline, a stress substrate, modulates carcinogenic pathways. Amino Acids 2008;35:681-690.

$\checkmark 13$ Liu W, Phang JM: Proline dehydrogenase (oxidase), a mitochondrial tumor suppressor, and autophagy under the hypoxia microenvironment. Autophagy 2012;8:1407-1409.

-14 Donald SP, Sun XY, Hu CA, Yu J, Mei JM, Valle D, Phang JM: Proline oxidase, encoded by p53-induced gene-6, catalyzes the generation of proline-dependent reactive oxygen species. Cancer Res 2001;61:1810-1815.

15 Hu CA, Donald SP, Yu J, Lin WW, Liu Z, Steel G, Obie C, Valle D, Phang JM: Overexpression of proline oxidase induces proline-dependent and mitochondria-mediated apoptosis. Mol Cell Biochem 2007;295:85-92.

16 Liu Y, Borchert GL, Surazynski A, Hu CA, Phang JM: Proline oxidase activates both intrinsic and extrinsic pathways for apoptosis: the role of ROS/superoxides, NFAT and MEK/ERK signaling. Oncogene 2006;25:5640-5647.

17 Martindale JL, Holbrook NJ: Cellular response to oxidative stress: signaling for suicide and survival. J Cell Physiol 2002;192:1-15.

18 Raha S, Robinson BH: Mitochondria, oxygen free radicals, and apoptosis. Am J Med Genet 2001;106:62-70.

19 Rasband WS: U. S. ImageJ., Institutes of Health, Bethesda, MAryland, USA., 1997-2015,

20 Peterkofsky B, Chojkier M, Bateman J: Determination of collagen synthesis in tissue and cell culture system. Immunochemistry of the extracellular matrix., 1982, pp 19-47.

-21 Lowry OH, Rosebrough NJ, Farr AL, Randall RJ: Protein measurement with the Folin phenol reagent. J Biol Chem 1951;193:265-275.

-22 Myara I, Charpentier C, Lemonnier A: Optimal conditions for prolidase assay by proline colorimetric determination: application to iminodipeptiduria. Clin Chim Acta 1982;125:193-205.

23 Liu Y, Borchert GL, Donald SP, Diwan BA, Anver M, Phang JM: Proline oxidase functions as a mitochondrial tumor suppressor in human cancers. Cancer Res 2009;69:6414-6422.

24 Liu W, Phang JM: Proline dehydrogenase (oxidase) in cancer. Biofactors 2012;38:398-406.

25 Surazynski A, Miltyk W, Prokop I, Palka J: Prolidase-dependent regulation of TGF $\beta$ (corrected) and TGF $\beta$ receptor expressions in human skin fibroblasts. Eur J Pharmacol 2010;649:115-119.

-26 Krishnan N, Dickman MB, Becker DF: Proline modulates the intracellular redox environment and protects mammalian cells against oxidative stress. Free Radic Biol Med 2008;44:671-681.

-27 Luo L, Zhang C, Zhao J, Wei Q, Li X: Effects of rapamycin on reduction of peridural fibrosis: an experimental study. Med Sci Monit 2015;21:482-488.

28 Motylewska E, Lawnicka H, Kowalewicz-Kulbat M, Sicinska P, Niedziela A, Melen-Mucha G, Stepien H: Interferon alpha and rapamycin inhibit the growth of pheochromocytoma PC12 line in vitro. Endokrynol Pol 2013;64:368-374.

29 Pandhare J, Donald SP, Cooper SK, Phang JM: Regulation and function of proline oxidase under nutrient stress. J Cell Biochem 2009;107:759-768.

-30 Lock HR, Sacks SH, Robson MG: Rapamycin at subimmunosuppressive levels inhibits mesangial cell proliferation and extracellular matrix production. Am J Physiol Renal Physiol 2007;292:F76-81. 


\section{Cellular Physiology Cell Physiol Biochem 2017;43:670-684

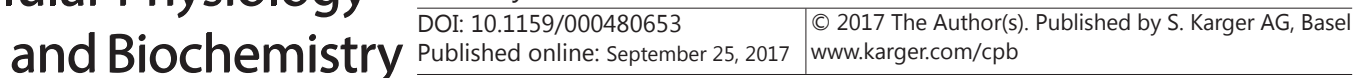 \\ Zareba et al.: A Viable Functional In Vitro Model for Proline Oxidase Research}

31 Kuo KL, Lin WC, Ho IL, Chang HC, Lee PY, Chung YT, Hsieh JT, Pu YS, Shi CS, Huang KH: 2-methoxyestradiol induces mitotic arrest, apoptosis, and synergistic cytotoxicity with arsenic trioxide in human urothelial carcinoma cells. PLoS One 2013;8:e68703.

-32 Rivera A, Maxwell SA: The p53-induced gene-6 (proline oxidase) mediates apoptosis through a calcineurindependent pathway. J Biol Chem 2005;280:29346-29354.

-33 Li HH, Zhao YJ, Li Y, Dai CF, yang XS, Jobe SO, Li XF, Pantankar MS, Magness RR, Zheng J: Estradiol $17 \beta$ and its metabolites stimulate cell proliferation and antagonize ascorbic acid-suppressed cell proliferation in human ovarian cancer cells., Reprod. Sci., 2014, 21, pp 102-111.

-34 Logan CY, Nusse R: The Wnt signaling pathway in development and disease. Annu Rev Cell Dev Biol 2004;20:781-810.

-35 Liu Y, Borchert GL, Surazynski A, Phang JM: Proline oxidase, a p53-induced gene, targets COX-2/PGE2 signaling to induce apoptosis and inhibit tumor growth in colorectal cancers. Oncogene 2008;27:6729-6737.

-36 Le A, Lane AN, Hamaker M, Bose S, Gouw A, Barbi J, Tsukamoto T, Rojas CJ, Slusher BS, Zhang H, Zimmerman LJ, Liebler DC, Slebos RJ, Lorkiewicz PK, Higashi RM, Fan TW, Dang CV: Glucose-independent glutamine metabolism via TCA cycling for proliferation and survival in B cells. Cell Metab 2012;15:110-121.

37 Phang JM, Liu W, Hancock C, Christian KJ: The proline regulatory axis and cancer. Front Oncol 2012;2:60.

38 Prasad S, Ravindran J, Aggarwal BB: NF-kappaB and cancer: how intimate is this relationship. Mol Cell Biochem 2010;336:25-37.

-39 Chen JA, Tanaka T: Charged residues on a flap-loop structure of Lactococcus lactis prolidase play critical roles in allosteric behavior and substrate inhibition. Biochim Biophys Acta 2011;1814:1677-1685.

40 Phang JM, Liu W: Proline metabolism and cancer. Front Biosci (Landmark Ed) 2012;17:1835-1845.

41 Polyak K, Xia Y, Zweier JL, Kinzler KW, Vogelstein B: A model for p53-induced apoptosis. Nature 1997;389:300-305.

42 Reiling JH, Sabatini DM: Stress and mTORture signaling. Oncogene 2006;25:6373-6383.

-43 Pandhare J, Cooper SK, Phang JM: Proline oxidase, a proapoptotic gene, is induced by troglitazone: evidence for both peroxisome proliferator-activated receptor gamma-dependent and -independent mechanisms. J Biol Chem 2006;281:2044-2052.

44 Liu W, Le A, Hancock C, Lane AN, Dang CV, Fan TW, Phang JM: Reprogramming of proline and glutamine metabolism contributes to the proliferative and metabolic responses regulated by oncogenic transcription factor c-MYC. Proc Natl Acad Sci U S A 2012;109:8983-8988.

45 Stoner GD, Merchant DJ: Amino acid utilization by L-M strain mouse cells in a chemically defined medium. In vitro 1972;7:330-343.

46 Priest RE, Davies LM: Cellular proliferation and synthesis of collagen. Lab Invest 1969;21:138-142.

47 Surazynski A, Miltyk W, Prokop I, Palka J: The effect of estrogen on prolidase-dependent regulation of HIF$1 \alpha$ expression in breast cancer cells. Mol Cell Biochem 2013;379:29-36.

-48 Gelse K, Pfander D, Obier S, Knaup KX, Wiesener M, Hennig FF, Swoboda B: Role of hypoxia-inducible factor 1 alpha in the integrity of articular cartilage in murine knee joints. Arthritis Res Ther 2008;10:R111.

-49 Bentovim L, Amarilio R, Zelzer E: HIF1 $\alpha$ is a central regulator of collagen hydroxylation and secretion under hypoxia during bone development. Development 2012;139:4473-4483.

-50 Wise DR, DeBerardinis RJ, Mancuso A, Sayed N, Zhang XY, Pfeiffer HK, Nissim I, Daikhin E, Yudkoff M, McMahon SB, Thompson CB: Myc regulates a transcriptional program that stimulates mitochondrial glutaminolysis and leads to glutamine addiction. Proc Natl Acad Sci U S A 2008;105:18782-18787.

-51 Dang CV: MYC, microRNAs and glutamine addiction in cancers. Cell Cycle 2009;8:3243-3245. 